\section{Gender and risk of depression in Saudi Arabia, a systematic review and meta-analysis}

\author{
Osama A. Alibrahim,' Nabilla Al-Sadat, ${ }^{2}$ \\ Nagi A. M. Elawad' \\ 'Al-Amal Hospital, Jeddah, Saudi Arabia \\ ${ }^{2}$ Department of Social and Preventive \\ Medicine, Faculty of Medicine, University \\ of Malaya, Kuala Lumpur, Malaysia
}

\section{Abstract}

Depression is one of the leading causes of mortality and morbidity worldwide. In the year 2000 depression accounted for $4.4 \%$ of the global disability adjusted life years (DALYs). The Kingdom of Saudi Arabia (KSA) has a population of 28 million people and is one of the countries experiencing demographic transition in its population structure. Improvements in socioeconomic status have been shown to be associated with increased chronic diseases including chronic mental diseases like depression, but still there is no comprehensive review summarizing the various reports currently existing in the literature. Although individual studies within Saudi Arabia have reported prevalence rates and risks, the quality of such studies need to be subjected to rigorous assessment and their findings pooled to give combined weighted evidence that will provide basis for targeted intervention. Pooled risks have the advantage of adjusting inherent variations within sampled populations and therefore providing more reliable estimates even though there are concerns about possible magnification of smaller individual risks.

\section{Introduction}

Depression is one of the leading causes of mortality and morbidity worldwide. ${ }^{1}$ In the year 2000 depression accounted for $4.4 \%$ of the global disability adjusted life years (DALYs). ${ }^{2}$ The Kingdom of Saudi Arabia (KSA) has a population of 28 million people. ${ }^{3} \mathrm{KSA}$ is one of the countries experiencing demographic transition in its population structure. Recent economic and industrial advancements have resulted in higher improved living conditions and longer life expectancy among KSA Nationals. ${ }^{4}$ Improvements in socioeconomic status have been shown to be associated with increased chronic diseases including chronic mental diseases like depression. Although many studies have reported prevalence and factors associated with depression in KSA, there is no comprehensive review that will summarize the various reports currently existing in the literature. There are debates and concern to know the true prevalence rates and factors associated with depression in Saudi Arabia and most other developing countries with populations in demographic transition. Although individual studies within Saudi Arabia have reported prevalence rates and risks, the quality of such studies need to be subjected to rigorous assessment and their findings pooled to give combined weighted evidence that will provide basis for targeted intervention. Pooled risks have the advantage of adjusting inherent variations within sampled populations and therefore providing more reliable estimates even though there are concerns about possible magnification of smaller individual risks.

The objective of this paper is therefore to provide a systematic review and meta-analysis of all available studies on the risks of depression in KSA.

\section{Materials and Methods}

We included studies that are observational assessing depression among Saudi Nationals either cross sectional, or cohort studies; as well, we included studies which participants are adults (17 years and older), or youths (13 years and older), both sexes, diagnosed with Depression or assessed to have depression during the course of the study. All ethnic groups and locations within Saudi Arabia were considered. We excluded studies done on children and those who are not Saudi national, as well Saudi Nationals who are not resident in Saudi Arabia but were on visit to the country.

Using the DSM IV criteria, we measured depression as reported in all considered studies as primary outcome reported, we also considered the followings as secondary outcomes: socioeconomic status, psychosocial factors and co-morbid medical conditions.

An exhaustive search was conducted in electronic databases for relevant studies, both published and unpublished. No language restrictions were used. Specifically, we searched the following sources:
- MEDLINE (1966-Date)
- EMBASE (1974-Date)
- Science Direct (1980-Date)
- PsycINFO/PsycLIT/ClinPSYC(1980-Date)
- Neuroscience Citation
- Proquest Psychology Journals
- ArabPsyNe
- PsiTri
- OVID

Specific search terms used were: depres
Correspondence: Osama A. Alibrahim, Al-Amal Hospital, P 0 Box 7822 Jeddah 21472, Kingdom of Saudi Arabia.

E-mail: doctoralibrahim@yahoo.com

Key words: depression, gender-related psychiatry.

Acknowledgments: the authors would like to thank the Department of Social and Preventive Medicine University of Malaysia and the management of Al-Amal Hospital, Jeddah, Saudi Arabia for their technical supports.

Conflict of interest: the authors report no conflicts of interest.

Received for publication: 15 October 2010 Accepted for publication: 25 October 2010

This work is licensed under a Creative Commons Attribution 3.0 License (by-nc 3.0).

(C) Copyright 0.A. Alibrahim et al., 2010

Licensee PAGEPress, Italy

Journal of Public Health in Africa 2010; 1:e7 doi:10.4081/jphia.2010.e7

sion, anxiety, mood disorder, Saudi Arabia, prevalence, factors, epidemiology, Kingdom of Saudi Arabia, elderly, youths, adolescents, general out-patient department, primary care centres.

In order to widen our search, we contacted primary authors of our identified relevant studies to check if they knew of other existing relevant studies. We also consulted proceedings for relevant studies and reference lists of identified studies. Free hand searching was conducted for studies in un-indexed or very recent journals and conference proceedings. Specifically, we searched the following local Saudi Arabian based medical journals: Saudi Medical Journal; Saudi Society of Family Medicine; Local Library of King Saudi University.

Two authors (OA and NE) independently assessed our potential relevant studies. Subsequently, we retrieved the full text reports of all studies considered by one or both authors as potentially relevant as well as those that were unclear. Each author used our standard eligibility form based on the inclusion and exclusion criteria to assess the studies. The carachteristics of included studies are reported in Table 1; the reasons of excluding studies are noted in Table 2.

Another pair of authors ( $\mathrm{OA}$ and $\mathrm{YM})$ independently extracted data from the studies using our pre-tested data extraction forms. We extracted the inclusion and exclusion criteria for the participants, total number of participants, number of dropouts and withdrawals and numbers diagnosed with each outcome. Any disagreements about data extracted were resolved by referring to the studies report and 
Table 1. Characteristics of included studies.

\begin{tabular}{|c|c|c|c|c|c|c|c|c|}
\hline Lead Author & Date & Place & Age & Population & Instrument & Sample & $\begin{array}{l}\text { Prevalence } \\
\text { of depression }\end{array}$ & Journal \\
\hline Al-Shammari & $1994-1995$ & Nationwide & 65 and older & $\begin{array}{l}\text { Elderly Saudi } \\
\text { patients }\end{array}$ & $\begin{array}{l}\text { Geriatric Depression } \\
\text { Scale (GDS) }\end{array}$ & 7970 & $39 \%$ & $\begin{array}{l}\text { International Journal } \\
\text { of Geriatric Psychiatry }\end{array}$ \\
\hline Becker & 2000-2002 & Riyadh & 17 and older & $\begin{array}{l}\text { Adult patients } \\
\qquad \mathrm{Qu}\end{array}$ & $\begin{array}{c}\text { Patient Health } \\
\text { uestionnaire Scale (PHQ). }\end{array}$ & 431 & $35.7 \%$ & $\begin{array}{c}\text { Social Psychiatry } \\
\text { and Psychiatric } \\
\text { Epidemiology }\end{array}$ \\
\hline Asal & 2005 & Taif & $16-20$ & $\begin{array}{c}\text { Secondary school } \\
\text { students }\end{array}$ & $\begin{array}{l}\text { Beck's Depression } \\
\text { Inventory (BDI) }\end{array}$ & 490 & $\begin{array}{c}\text { (Male 5-55\%) } \\
\text { (Female 0-49\%) }\end{array}$ & Neurosciences \\
\hline
\end{tabular}

Table 2. Excluded studies and reasons for exclusion.

\begin{tabular}{llll}
$\begin{array}{l}\text { Lead Author } \\
\text { Bassiony }\end{array}$ & $\begin{array}{l}\text { Study Date } \\
\text { Abumadini }\end{array}$ & $\begin{array}{l}\text { Journal } \\
\text { Depression and Anxiety }\end{array}$ & $\begin{array}{l}\text { Reason for exclusion } \\
\text { Did not report depression prevalence and risk by gender } \\
\text { of respondents. }\end{array}$ \\
\hline Al-Khatami & $2000-2002$ & Journal of Family \& Community Medicine & $\begin{array}{l}\text { Methodology was not adequately described. } \\
\text { Did not report depression prevalence and risk by gender of respondents. }\end{array}$ \\
Al-Gelban & 2000 & Saudi Medical Journal & $\begin{array}{l}\text { Did not report depression prevalence and risk by gender } \\
\text { of respondents. }\end{array}$ \\
\hline
\end{tabular}

by discussion. Where data were insufficient or missing, we contacted the study's authors.

For continuous outcomes, we extracted the arithmetic mean values, standard deviations, and number of participants on whom the outcome was assessed.

For count data, we extracted the total number of events. If this information was not available, we extracted alternative summary statistics such as odd ratios and confidence intervals if available.

A pair of authors (OA and NE) independently assessed the presence of bias in all our included studies. We used the guidelines for the reporting of observational studies to assess the presence of bias in our included studies. The results of the risk of bias are presented in the risk of bias table.

We expressed results of dichotomous outcomes as risk ratio (RR) with $95 \%$ confidence intervals (CI). Outcomes on continuous scales of measurement are expressed using mean difference (MD) and standardised mean difference (SMD) if different scales have been used.

Where we found some data are missing, we contacted the study's authors for the missing data. If there was no response or there was response but could not provide data, we excluded such outcomes from our analysis.

Data was entered into Review Manager ${ }^{5}$ by one of the authors (OA) and cross-checked by other two authors (NE and YM). We presented results with $95 \%$ confidence intervals. We also compared all odd ratios against other studies.
By using forest plot and performing the $\chi^{2}$ test for heterogeneity and using a $P$ value of 0.10 to determine statistical significance, we assessed the presence of statistical heterogeneity among studies. The $\mathrm{I}^{2}$ test was also used to asses inconsistencies within studies, a value greater than $50 \%$ was considered as substantial heterogeneity. If we found a low level moderate heterogeneity, we used the random effect model to adjust. If there was significant statistical heterogeneity, we explored the possible sources of heterogeneity by removing studies with low quality and by using subgroup analyses for studies according to the age of the participants. Sensitivity analyses were also done to assess the robustness of the metaanalysis among the studies.

\section{Results}

A total of 730 studies were retrieved; 685 studies were excluded, among these 653 titles were not relevant to our review, 5 were drug trials, were non-relevant abstracts and 7 were duplicates. Forty-five full text were assessed and out of these 7 papers met the inclusion criteria for this review.

Five of the studies assess depression among adults in primary care setting, while 3 studies were community based surveys assessing depression among young people in Saudi Arabia (Figure 1).

Al-Shammari ${ }^{5}$ reported on 7970 Elderly
Saudi patients aged 65 and above. The study was cross sectional national survey to assess prevalence of depression among Saudi elderly. The survey was conducted between January 1994 and December 1995, the geriatric depression scale (GDS) was used for the evaluation.

Becker $^{6}$ reported on 431 Saudi patients in Riyadh KSA. The study was cross sectional survey to assess correctly diagnosed somatisation and depression by primary care physicians among adult primary care patients. The survey was conducted between September 2000 and April 2001, the patient health questionnaire scale (PHQ) for assessment mental disorders was used for the evaluation.

$\mathrm{Asal}^{7}$ reported on 490 Saudi secondary schools students in Taif KSA. The study was cross sectional survey to assess depression among young people aged 16-20 using the Arabic Beck's depression inventory (BDI). The survey was conducted between January and May 2005.

\section{Excluded studies}

Bassiony ${ }^{8}$ reported on 98 Saudi patients in Eastern province KSA. The study was cross sectional survey to assess prevalence of depression among patients with social anxiety disorder symptoms referred to out psychiatric out-patients care department.

Abumadini $^{9}$ reported on 632 Saudi patients in King Fahad Hospital University (KFHU) in Eastern Saudi Arabia, KSA. The study was cross sectional survey to assess prevalence of depression among patients referred to psychi- 

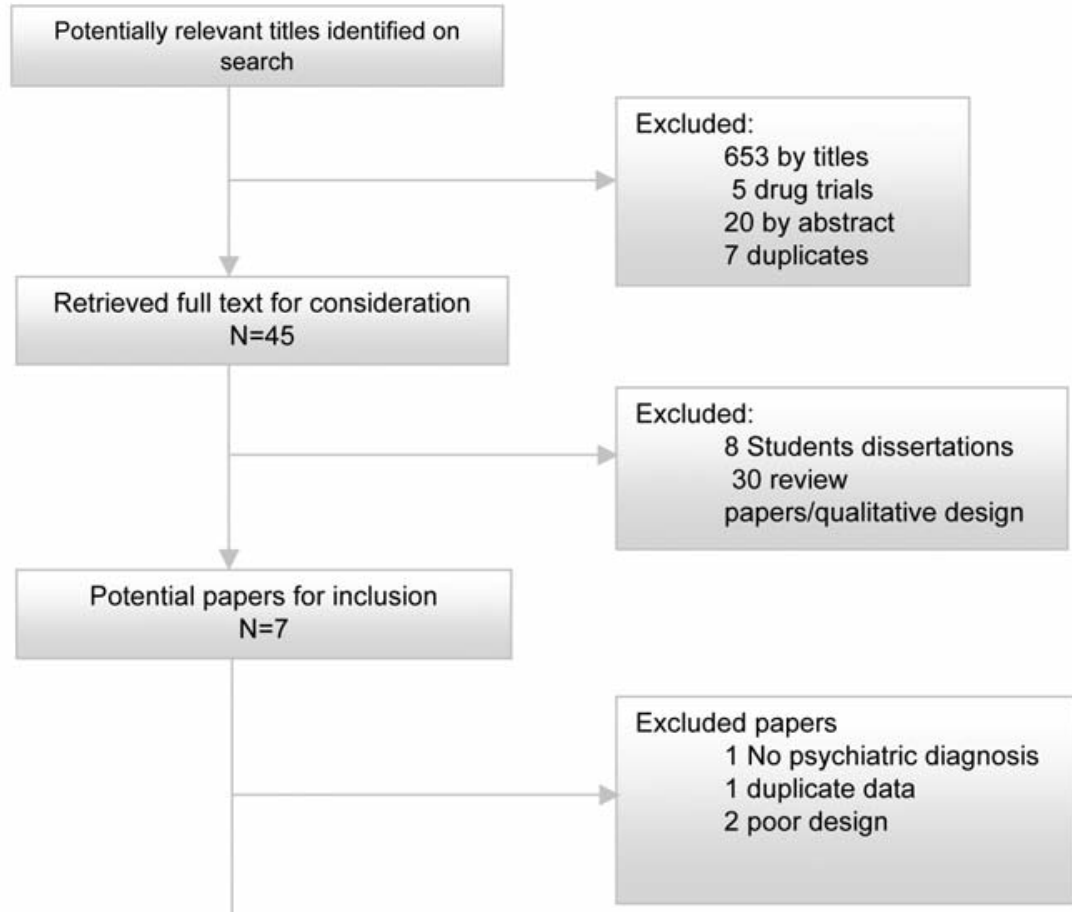

cluded studies $\mathrm{N}=3$
Figure 1. Articles selection flow chart. Included studies.

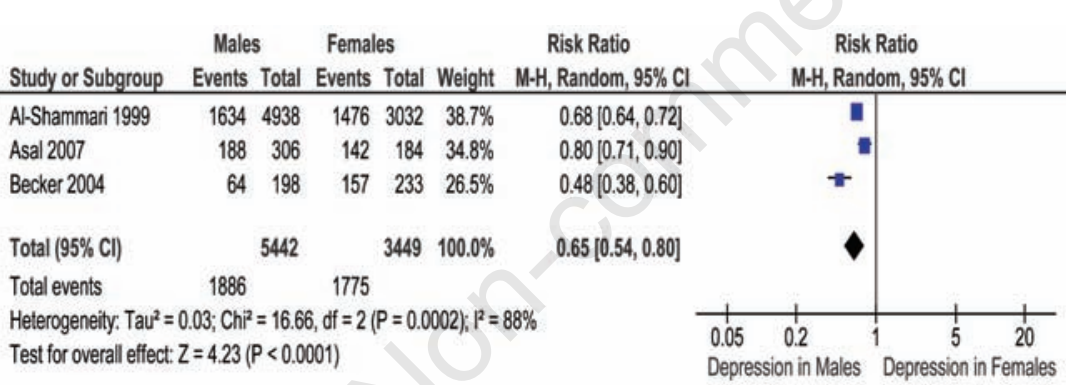

Figure 2. Prevalence of depression by gender in Saudi Arabia. the first time a review and meta-analysis is done to assess pooled risk of depression in Saudi Arabia (Figure 2). Reviews conducted in other Middle East countries to assess pooled risk of depression are scarce as well. In Iran a review reported a combined prevalence of major depressive disorder to be $4.1 \%$ and women were as well more likely to be depressed RR: 1.95 (CI: 1.55-2.45) compared with males. ${ }^{12}$ It was not possible in this review to compare prevalence of depression by spatial geographical distribution as all but one study were conducted in urban areas. Apart from gender, biological, psychological and social variables are known to affect prevalence of depression.

\section{Limitations}

Although all efforts were made to search and retrieve all potential papers for inclusion in this review, we cannot absolutely claim to have unearthed all potentially relevant papers for inclusion in this review. We also noted the existence of substantial heterogeneity among our included studies, but we viewed this from the fact that studies with large and small sample sizes were included. We should further state that use of meta-analysis of observational studies is still a subject of intense debate and caution must be exercised when application of such findings into practice.

\section{Conclusions}

Unlike it is previously thought, risk of developing depression in among Saudi nationals regardless of age did not appear to be high. Males are less likely to be depressed compared to women. It is imperative to note that this is the first meta-analysis reporting low risk of depression in Saudi Arabia. More reviews will be needed to validate our findings. Efforts most be sustained to maintained targeted intervention to sustain low risks of depression in Saudi Arabia.

\section{Implications for practice}

Even though depression risk appears to be low, nonetheless it remains a challenge to overcome in both clinical and community settings. The findings of this study should be kept in mind by physicians, as low risk does not mean no risk. Depression should be considered among top differentials among at risk groups. Public health policy makers should use the findings of this review to sustain targeted intervention with the view to further reduce risks and impact of depression in the society.

\section{Implications for research}

This review provides valid point estimates 
from studies assessed to be of sound quality. However quantitative estimates do not always answer the questions "why" or "how". There is a need for qualitative exploration of elements leading to depression among strata of demographic variables in Saudi Arabia.

\section{References}

1. Murray CJL, Lopez AD. The global burden of disease: a comprehensive assessment of mortality and disability from diseases, injuries and risk factors in 1990, and projected to 2020. Harvard University Press, Cambridge, MA, USA 1996.

2. Meyer C. Depressive disorders were the fourth leading cause of global disease burden in the year 2000. Evid Based Mental
Health 2004;7:123.

3. United Nations. Department of Economic and Social Affairs, Population Division. The 2008 Revision (2009). Home page address: http:/www.un.org/esa/population/

4. Population Reference Bureau. 2010 World Population Data Sheet. Available at: http://www.prb.org/Publications/Datasheet s/2010/2010wpds.aspx

5. Al-Shammari SA, Al-Subaie A. Prevalence and correlates of depression among Saudi elderly. Int J Geriatr Psychiatry 1999;14: 739-47.

6. Becker SM. Detection of somatization and depression in primary care in Saudi Arabia. Soc Psychiatry Psychiatr Epidemiol 2004;39:962-6.

7. Asa ARA, Abdel-Fattah MM. Prevalence, symptomatology, and risk factors for depression among high school students in
Saudi Arabia. Neurosciences 2007;12:8-16.

8. Bassiony MM. Social anxiety disorder and depression in Saudi Arabia. Depress Anxiety 2005;21:90-4.

9. Abumadini MS. Depressive disorders in psychiatric outpatient clinic attendees in eastern Saudi Arabia. J Fam Community Med 2003;10:1-9.

10. Al-Gelban KS. Depression, anxiety and stress among Saudi adolescent school boys. J R Soc Promot Health 2007;127:33-7.

11. Al-Khathami AD, Ogbeide D0. Prevalence of mental illness among Saudi adult primary-care patients in Central. Saudi Med J 2002;23:721-4.

12. Sadeghirad B, Haghdoost AA, AminEsmaeili M, et al. Epidemiology of major depressive disorder in Iran: a systematic review and meta-analysis. Int J Preventive Med 2010;1:81-91. 